\title{
Retraction
}

\section{Retracted: Anaerobic Treatment of Palm Oil Mill Effluent in Pilot-Scale Anaerobic EGSB Reactor}

\author{
BioMed Research International \\ Received 25 February 2018; Accepted 25 February 2018; Published 1 March 2018 \\ Copyright (c) 2018 BioMed Research International. This is an open access article distributed under the Creative Commons \\ Attribution License, which permits unrestricted use, distribution, and reproduction in any medium, provided the original work is \\ properly cited.
}

BioMed Research International has retracted the article titled "Anaerobic Treatment of Palm Oil Mill Effluent in Pilot-Scale Anaerobic EGSB Reactor" [1]. The article was found to be a dual publication of the following published article: "Jin Wang, Qaisar Mahmood, Jiang-Ping Qiu, et al., "Zero Discharge Performance of an Industrial Pilot-Scale Plant Treating Palm Oil Mill Effluent," BioMed Research International, vol. 2015, Article ID 617861, 9 pages, 2015. doi:10.1155/2015/617861."

\section{References}

[1] J. Wang, Q. Mahmood, J.-P. Qiu, Y.-S. Li, Y.-S. Chang, and X.D. Li, "Anaerobic Treatment of Palm Oil Mill Effluent in PilotScale Anaerobic EGSB Reactor," BioMed Research International, vol. 2015, Article ID 398028, 7 pages, 2015. 


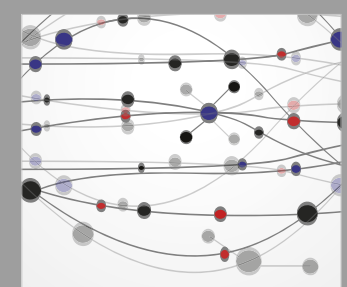

The Scientific World Journal
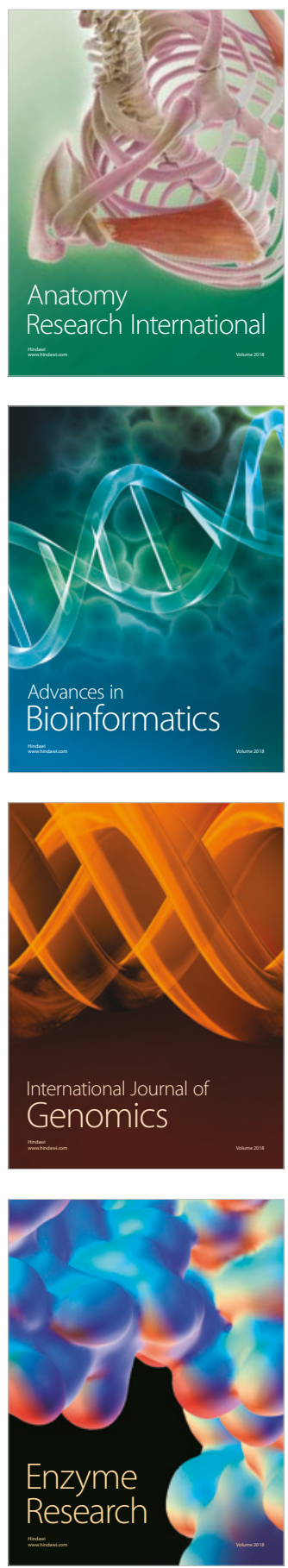
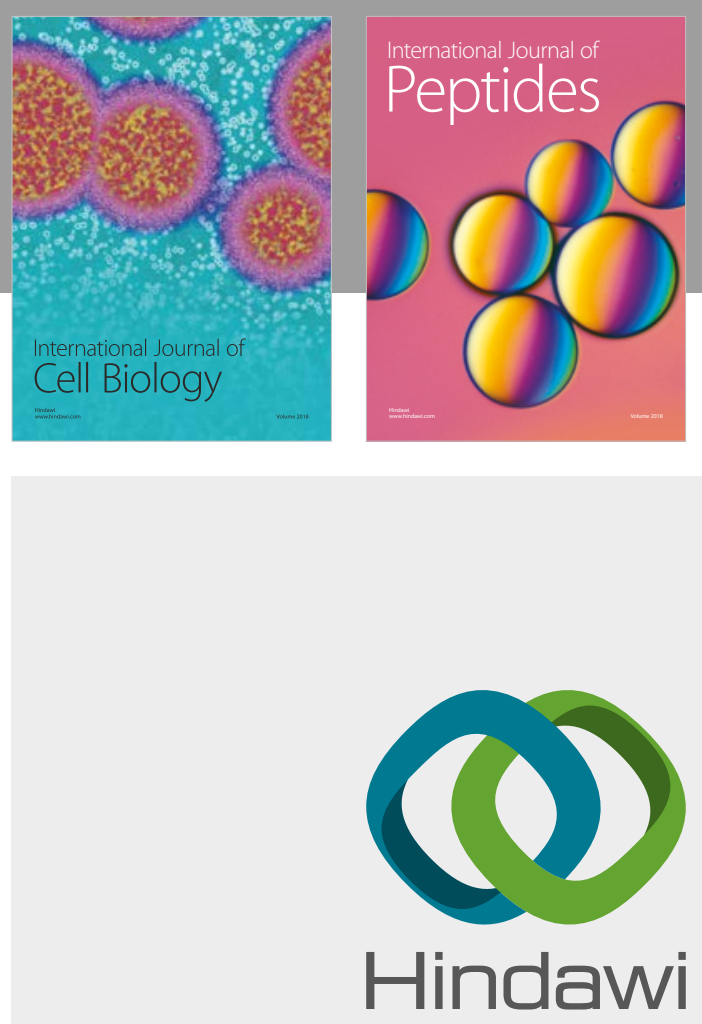

Submit your manuscripts at

www.hindawi.com
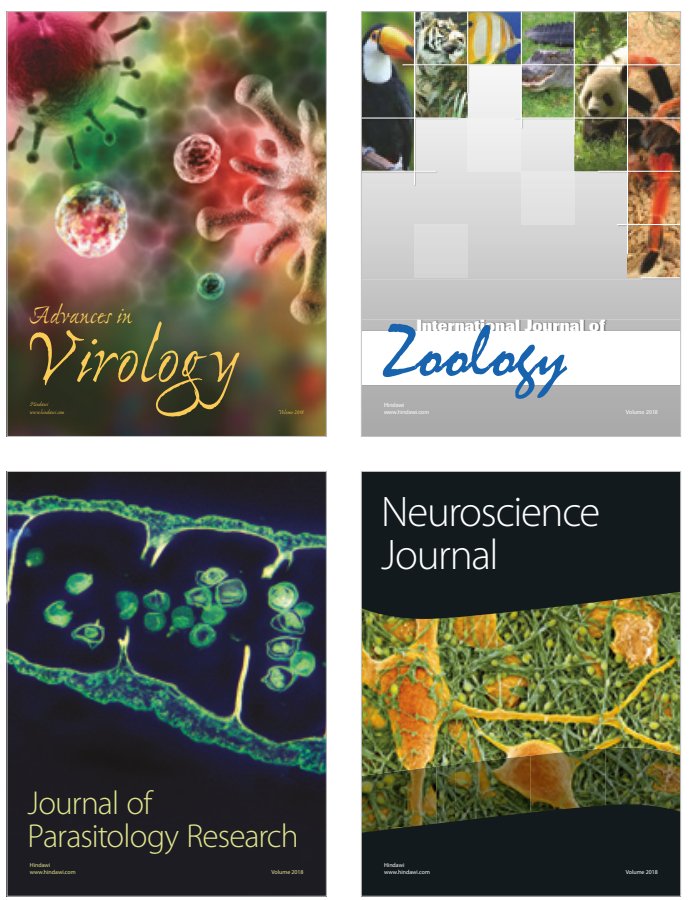
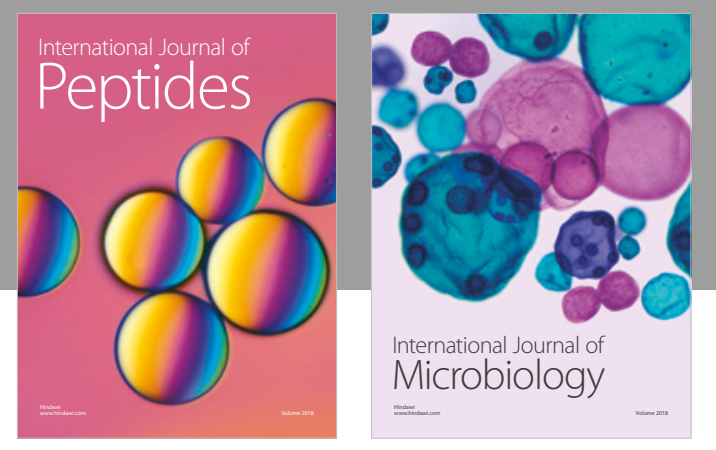

nternational Journal of Microbiology
Journal of
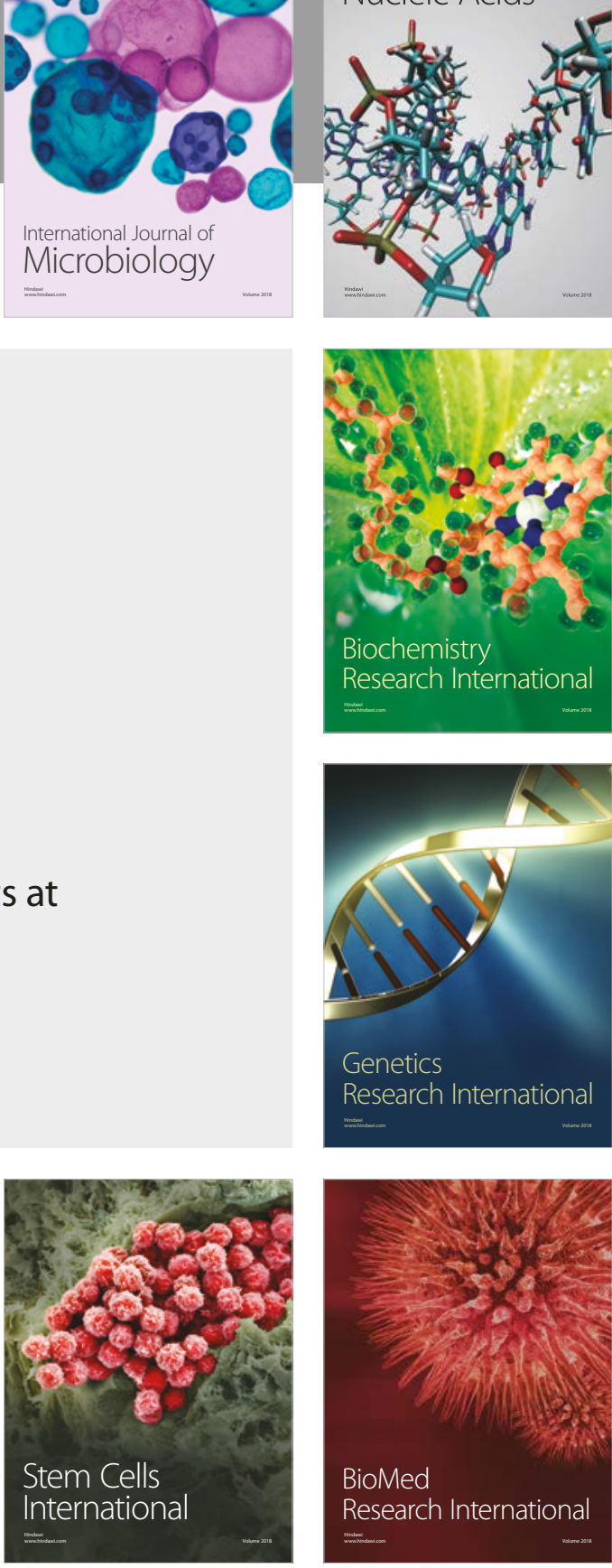
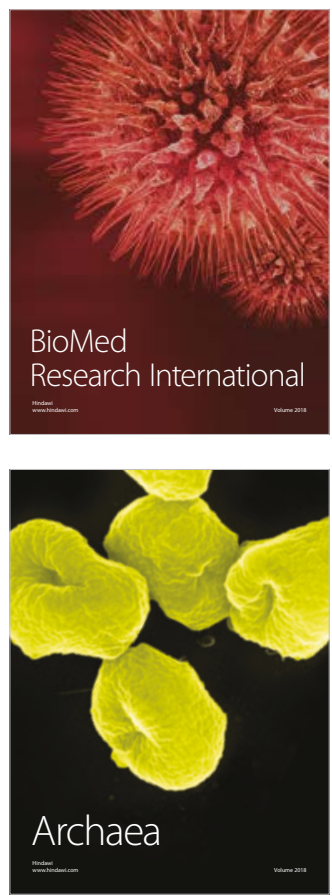